\title{
Magnet design for an ultralow emittance storage ring
}

\author{
F. Saeidi, ${ }^{1,2,{ }^{*}}$ M. Razazian, ${ }^{1}$ J. Rahighi, ${ }^{1}$ and R. Pourimani ${ }^{2}$ \\ ${ }^{1}$ Iranian Light Source Facility (ILSF), Institute for Research in Fundamental Sciences (IPM), \\ P.O. Box 19395-5746 Tehran, Iran \\ ${ }^{2}$ Department of Physics, Faculty of Science, Arak University, Arak 38156, Iran
}

(Received 28 December 2015; published 22 March 2016)

\begin{abstract}
The Iranian Light Source Facility (ILSF) is a new $3 \mathrm{GeV}$ synchrotron radiation laboratory which is in the design stage. The ILSF storage ring (SR) is based on a Five-Bend Achromat (5BA) lattice providing an ultra-low beam emittance of $0.48 \mathrm{~nm}$ rad. The ring is comprised of 100 pure dipole magnets, 320 quadrupoles, and 320 sextupoles with additional coils for dipole and skew quadrupole correctors. In this paper, we present some design features of the SR magnets and discuss the detailed physical design of these electromagnets. The related electrical and cooling calculations and mechanical design issues have been investigated as well.
\end{abstract}

DOI: 10.1103/PhysRevAccelBeams.19.032401

\section{INTRODUCTION}

The Iranian Light Source Facility (ILSF) is the first Iranian synchrotron light laboratory which is in the design stage and will be built in the city of Qazvin located $150 \mathrm{~km}$ west of Tehran [1-2]. The ultralow beam emittance storage rings is characterized by the multibend achromat lattice structure, which improves the brightness 2-3 orders of magnitude higher than the present-day synchrotron radiation sources [3-8]. The designed ILSF storage ring lattice is in regard to 5BA lattice. The circumference is $528 \mathrm{~m}$ with 20 super periods and the horizontal emittance of the electron beam would be $0.48 \mathrm{~nm}$ rad. Each super period includes 5 pure dipole, 16 quadruple, and 16 sextupole magnets. The single role magnets, employed in the lattice, result in low fabrication cost by local industries, easy alignment and less sensitivity of the lattice to the errors in comparison with the high field and combined ones. The mechanical design of one super period of the ILSF storage ring lattice is shown in Fig. 1. Further information about the storage ring can be found in Refs. [9-10].

Although the radiated photon beam from the low field dipoles would be useful for the several experiments in the soft $\mathrm{x}$-ray region, the designed lattice can provide the required high energy hard $\mathrm{x}$-ray photon beam with the practice of the superbend magnet which additionally helps emittance reduction [11-14]. Furthermore, the lack of straight sections is also a significant concern in the ILSF machine, since there will be totally 17 free straight sections for insertion devices. Therefore, the superbend solution

\footnotetext{
*Corresponding author.

farhad.saeidi@ipm.ir, saeidi.farhad@gmail.com

Published by the American Physical Society under the terms of the Creative Commons Attribution 3.0 License. Further distribution of this work must maintain attribution to the author $(s)$ and the published article's title, journal citation, and DOI.
}

providing high capacity, serves up to 20 beam lines in the ring. These features were the main motivations for the ILSF to employ the superbend magnet. Further information about the storage ring including the superbend magnet can be found in Ref. [10].

The experiences of R\&D fabricated magnet prototypes with home industries have demonstrated that the locally available laminated low carbon steel ST14 with standard number of 1.0338 can be employed as the main material for fabrication of all SR magnets [15]. The measured B-H curve and relative permeability graphs of ST14 are shown in Fig. 2. They indicate that the saturation field of the ST14 material is about $1.6 \mathrm{~T}$ where the relative permeability decreases to less than 500 [16].

The physical analysis of the SR magnets in two and three dimensions (2D and 3D) will be discussed. The magnetic field quality, harmonic and statistical analysis, and end pole chamfering process are included. It should be noted that the FEMM [17], POISSON [18], MERMAID [19], and RADIA [20] software programs are used for the magnet design. The related electrical and cooling calculations and the mechanical issues are described respectively. Whereas the detailed design of the superbend magnet was inspected in Ref [10], only the main low field magnets are deliberated here.

\section{STORAGE RING MAGNETS}

The ILSF $3 \mathrm{GeV}$ storage ring with the circumferences of $528 \mathrm{~m}$ and 20 super periods, consists of 100 dipole magnets of one type, 320 quadrupoles, and 320 sextupoles. Arrangement of the SR magnets in a half super period of the ring is shown in Fig. 3. The pure dipoles are set to be run in series with a common power supply while the quadrupoles and sextupoles are individually powered [21].

It should be pointed out that magnet parameters are defined by the following equations: 


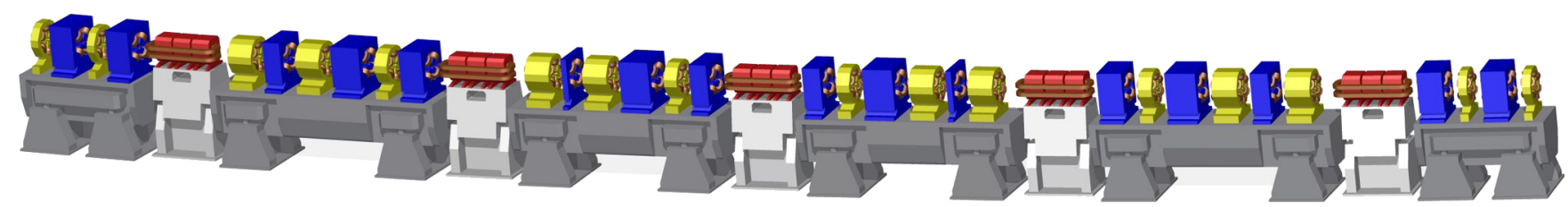

FIG. 1. Mechanical design of one super period of the ILSF storage ring lattice. The red, blue and yellow magnets are dipoles, quadrupoles, and sextupoles, respectively.
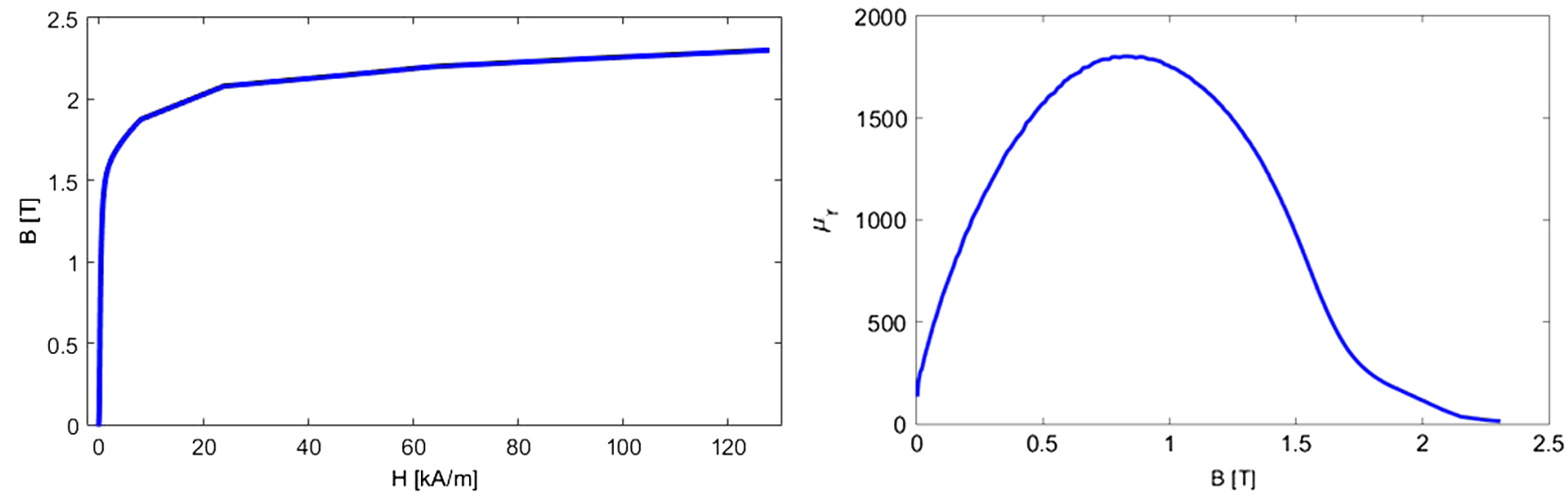

FIG. 2. Measured B-H curve (left) and relative permeability of ST14 (right).

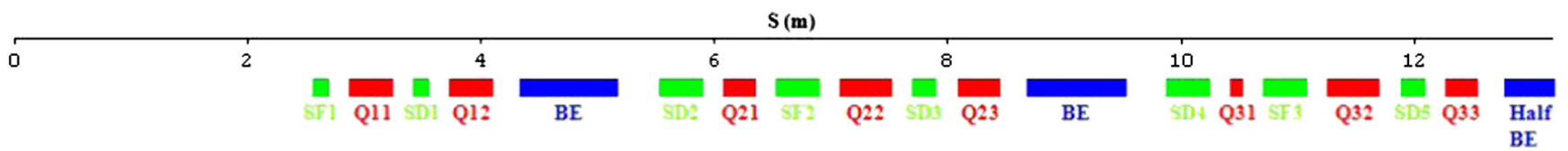

FIG. 3. Arrangement of the magnets in a half super period of the ILSF storage ring. Blue, red and green colors represent dipole, quadrupole, and sextupole magnets, respectively.

$$
K=\frac{B^{\prime}}{B \rho}=0.29979 \frac{B^{\prime}}{E(\mathrm{GeV})} \quad \text { where } B^{\prime}=\left.\frac{\partial B_{y}}{\partial x}\right|_{y=0},
$$

$M=\frac{B^{\prime \prime}}{B \rho}=0.29979 \frac{B^{\prime \prime}}{E(\mathrm{GeV})}$ where $B^{\prime \prime}=\left.\frac{\partial^{2} B_{y}}{\partial x^{2}}\right|_{y=0}$,

where $K$ is the quadrupole strength of, $M$ is the sextupole strength, $B^{\prime}$ is the field gradient and $B^{\prime \prime}$ denotes the sextupole component. The magnetic field expansion at mid-plane $(y=0)$ is;

$B_{y}(x)=\sum_{n=1}^{n=\infty} B_{n}=B_{1}+B^{\prime} x+B^{\prime \prime} \frac{x^{2}}{2}+\cdots=\sum_{n=1}^{n=\infty} b_{n} x^{n-1}$,

where $n$ is the order of multipole component and $b_{n}$ is the multipole coefficient.

Dipole magnet with the magnetic field of $0.75 \mathrm{~T}$ and the magnetic length of $0.84 \mathrm{~m}$ bends the beam 3.60 degrees.
Main specifications of the dipole are given in Table I. Focusing is performed through exercising 16 quadrupoles in a super period grouped in 8 families with the maximum gradient of $25 \mathrm{~T} / \mathrm{m}$. The natural chromaticity is corrected close to a positive value by the use of 16 sextupoles grouped in 8 families with the maximum strength of $1200 \mathrm{~T} / \mathrm{m}^{2}$. Main specifications of the quadrupole and sextupole magnets are given in Table II. In order to correct

TABLE I. Main parameters of the ILSF $3 \mathrm{GeV}$ storage ring dipole magnets.

\begin{tabular}{lcc}
\hline \hline Dipole & Unit & Value \\
\hline Magnetic Length & $\mathrm{m}$ & 0.84 \\
Magnetic Field & $\mathrm{T}$ & 0.748 \\
Gap & $\mathrm{mm}$ & \pm 15 \\
Deflection Angle & Degree & 3.6 \\
Bending Radius & $\mathrm{m}$ & 13.369 \\
Field Gradient & $\mathrm{T} / \mathrm{m}$ & 0.000 \\
Sextupole component & $\mathrm{T} / \mathrm{m}^{2}$ & 0.000 \\
\hline \hline
\end{tabular}


TABLE II. Main parameters of the ILSF $3 \mathrm{GeV}$ storage ring quadrupole and sextupole magnets. The aperture radius is $26 \mathrm{~mm}$ for all magnets.

\begin{tabular}{lcrrrr}
\hline \hline & $\begin{array}{r}\text { Magnetic } \\
\text { Quadrupole length }(\mathrm{m})\end{array}$ & \multicolumn{1}{c}{$B^{\prime}$} & & $\begin{array}{r}\text { Magnetic } \\
(\mathrm{T} / \mathrm{m})\end{array}$ & $\begin{array}{c}B^{\prime \prime} \\
\left(\mathrm{T} / \mathrm{m}^{2}\right)\end{array}$ \\
\hline Q11 & 0.360 & 21.649 & SF1 & 0.130 & 835.233 \\
Q12 & 0.360 & -22.609 & SF2 & 0.360 & 1162.935 \\
Q21 & 0.270 & 16.949 & SF3 & 0.360 & 1127.157 \\
Q22 & 0.440 & 20.052 & SD1 & 0.130 & -1149.060 \\
Q23 & 0.360 & -20.951 & SD2 & 0.360 & -995.105 \\
Q31 & 0.100 & 6.515 & SD3 & 0.200 & -1008.070 \\
Q32 & 0.440 & 24.782 & SD4 & 0.360 & -1034.110 \\
Q33 & 0.270 & -19.142 & SD5 & 0.200 & -1024.820 \\
\hline \hline
\end{tabular}

the distorted orbit and coupling correction, additional windings in 200 sextupole magnets are employed [9].

\section{DIPOLE}

The $\mathrm{C}$ type ILSF dipole magnet is designed in 3 adjacent straight sections rather than one curved shape to simplify the fabrication procedure of the magnet core and coils [22]. The dipole is divided into three straight sections all with the same specifications, see Fig. 4. This is rather feasible since the short bulk magnet yields a smaller sagitta, smaller pole width and significant savings in the amount of iron core material. One shared coil is utilized for all three sections. The middle low field dipole section will be replaced with a wider high field dipole with extra individual coils in the superbend magnet. On the side of keeping the integrated

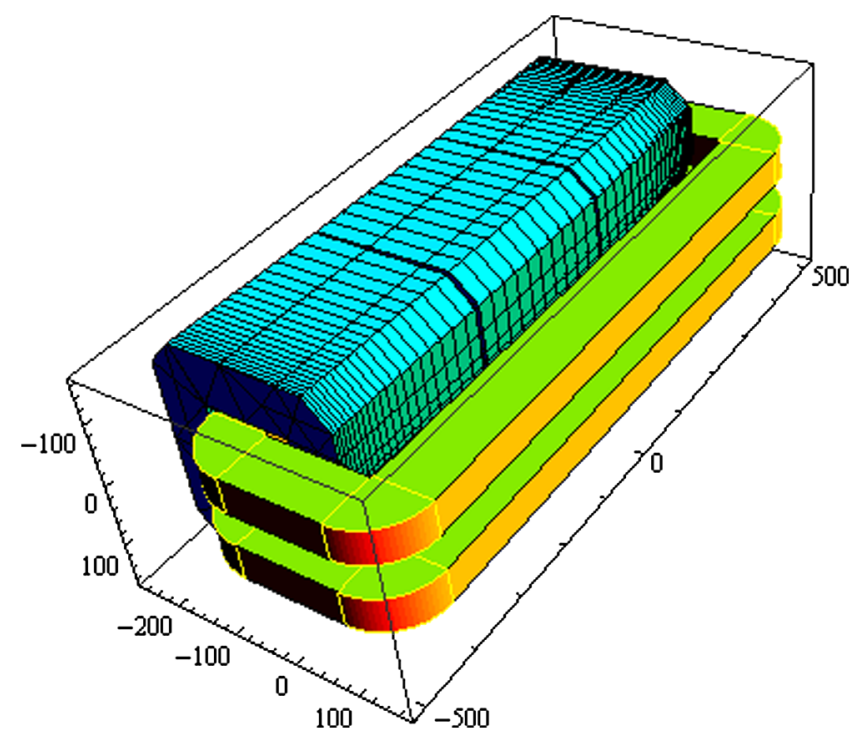

FIG. 4. 3D design of the main dipole magnet. Every dipole is divided into three sections, that each bends the beam 1.2 degrees. The angle between the middle section and lateral sections is 1.2 degrees. The scale is millimeter.

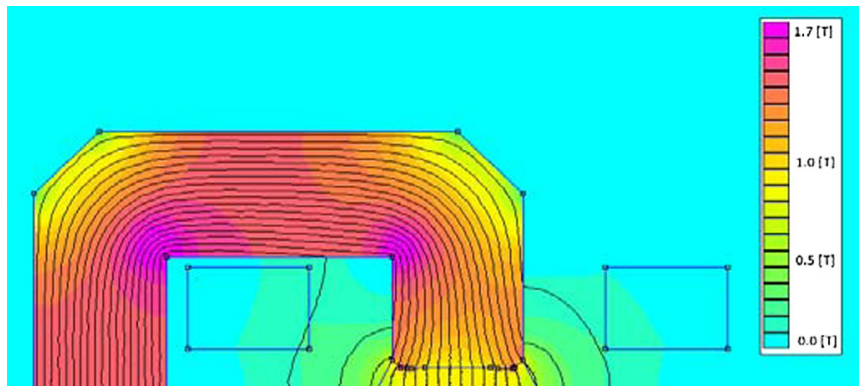

FIG. 5. Magnetic field inside a half of the SR dipole magnet. The colors in the yoke correspond to the field values given on the legend.

field constant, the higher the magnetic field the smaller the yoke length [23].

The horizontal good field region (GFR) in the dipole together with the small sagitta of each section is $\pm 14 \mathrm{~mm}$ with the required field quality of $1 \times 10^{-4}$. The vertical GFR of $\pm 11 \mathrm{~mm}$, and utilizing $2 \mathrm{~mm}$ clearance between the vacuum chamber and the magnet pole tip, results in half gap of $15 \mathrm{~mm}$ [24]. Figure 5 shows the simulated magnetic field inside one half of the dipole. Assigning nonsymmetric standard shims, the field quality outdoes $0.01 \%$ within the GFR, see Fig. 6 . Its corresponding 2D mechanical layout is plotted in Fig. 7 indicating the total lamination dimensions of $320 \times 360 \mathrm{~mm}^{2}$ with $1 \mathrm{~mm}$ thickness. It should be mentioned that the space between the coils and the yoke is reserved for the wide high field inserted magnet pole [10].

The higher order multipole components due to the finite pole profile and the saturation of the material considerably affect the dynamic aperture. Normalized systematic higher order multipoles obtained with the POISSON code [18] are depicted in Fig. 8. In general, the sextupole component has the greatest effect on the dynamic aperture, it being as low

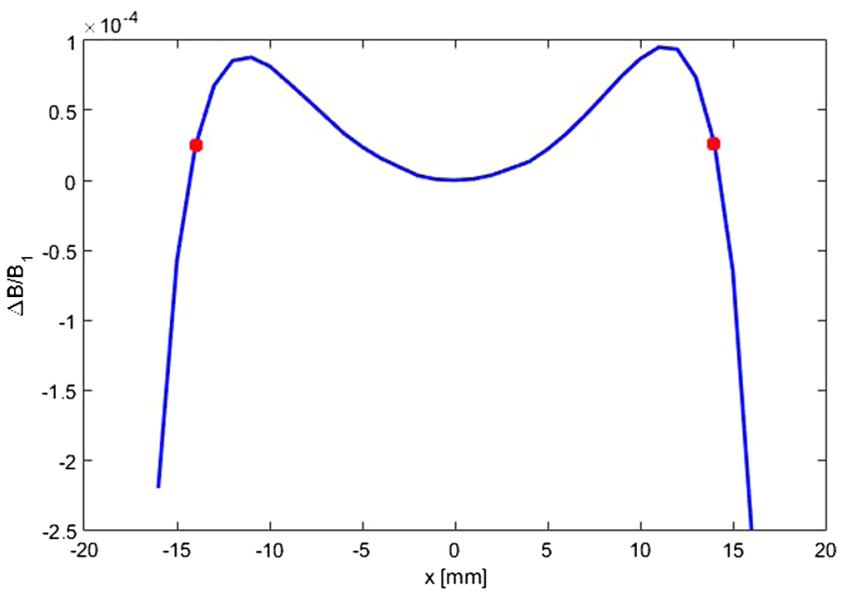

FIG. 6. Field quality of the 2D designed dipole magnet vs horizontal distance. The red points represent $\pm 14 \mathrm{~mm}$ GFR. 


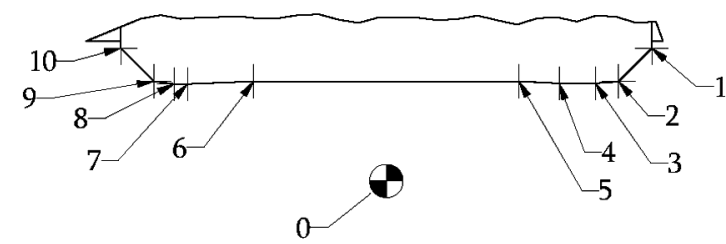

B

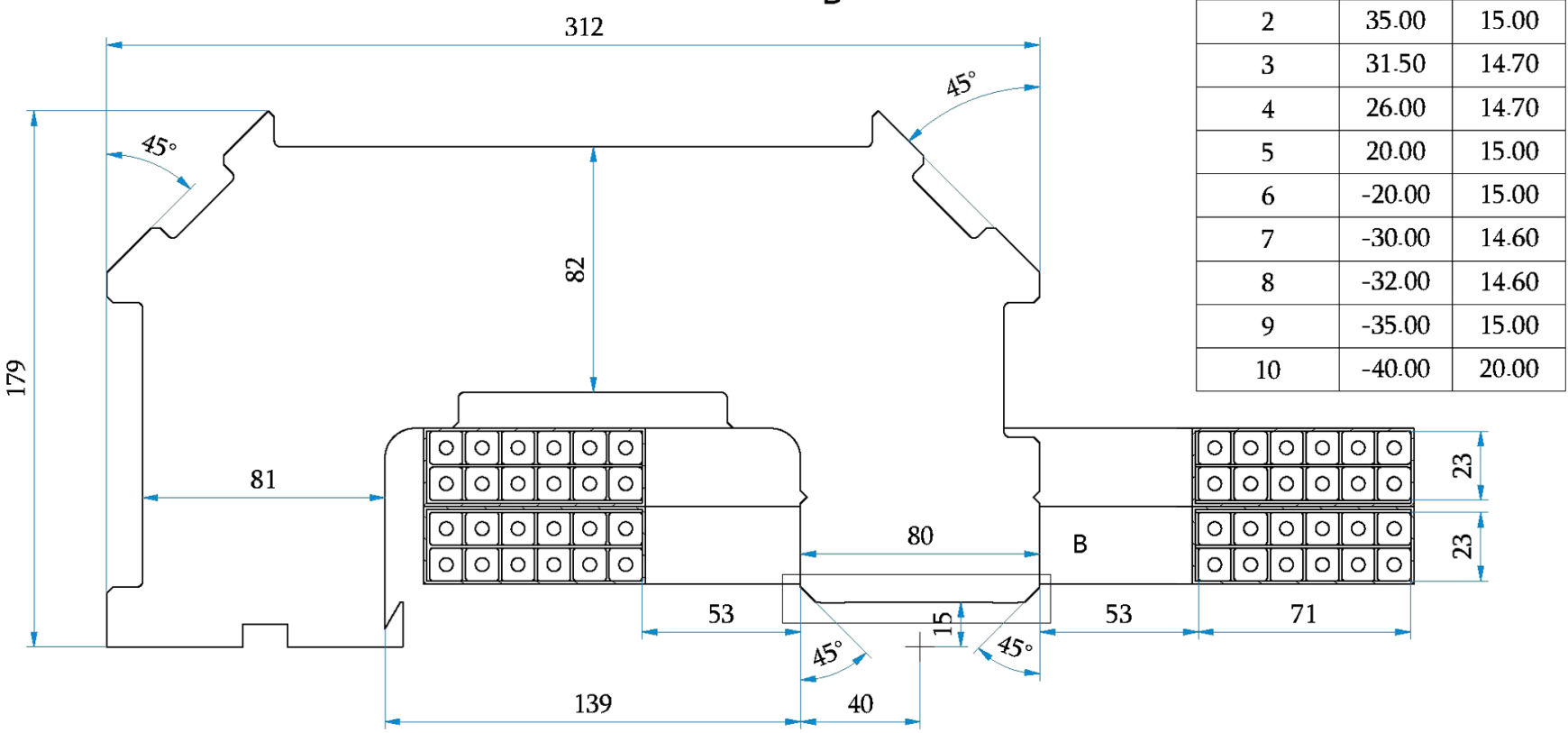

FIG. 7. Lamination and coils dimensions of the SR dipole magnet and the pole profile coordinates. The scale is millimeter.

as $1.7 \times 10^{-4}$ at the GFR of $14 \mathrm{~mm}$, means such an effect can be neglected, see Ref. [9].

Moreover, the saturation test was done by sketching the magnetic field versus the current as shown in Fig. 9. It depicts that the operation current of the low field dipole is

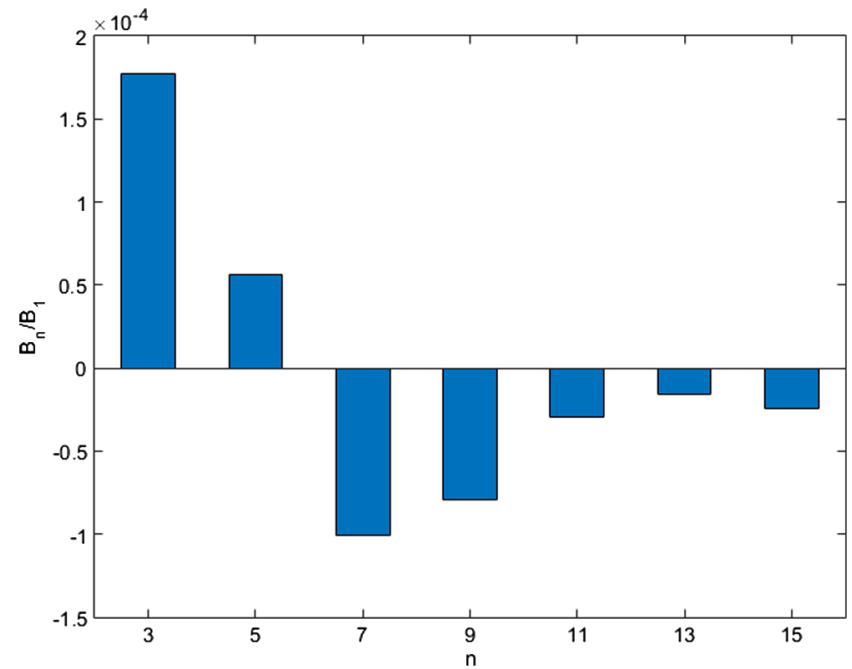

FIG. 8. Normalized systematic higher order multipoles of the SR dipole magnet at the GFR of $14 \mathrm{~mm}$.
$382 \mathrm{~A}$, and the deviation from the corresponding linear curve is less than $0.4 \%$.

The pole deflection in the presence of the magnetic force between the poles [25] and the weight of laminations is evaluated for the designed dipole and the result is displayed in Fig. 10. As shown, the maximum pole deflection is less

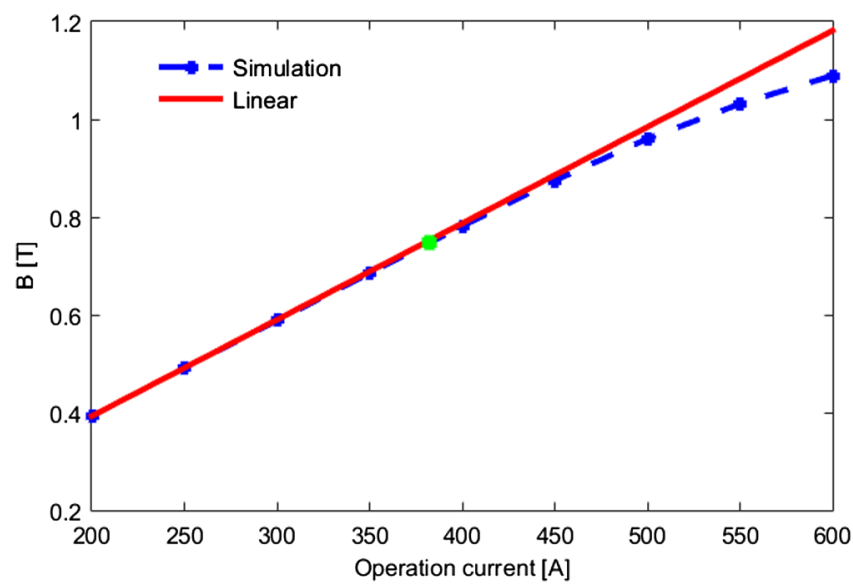

FIG. 9. Magnetic field as a function of the operation current of the low field dipole magnet. The green filled circle indicates the 2D designed dipole operation current. 


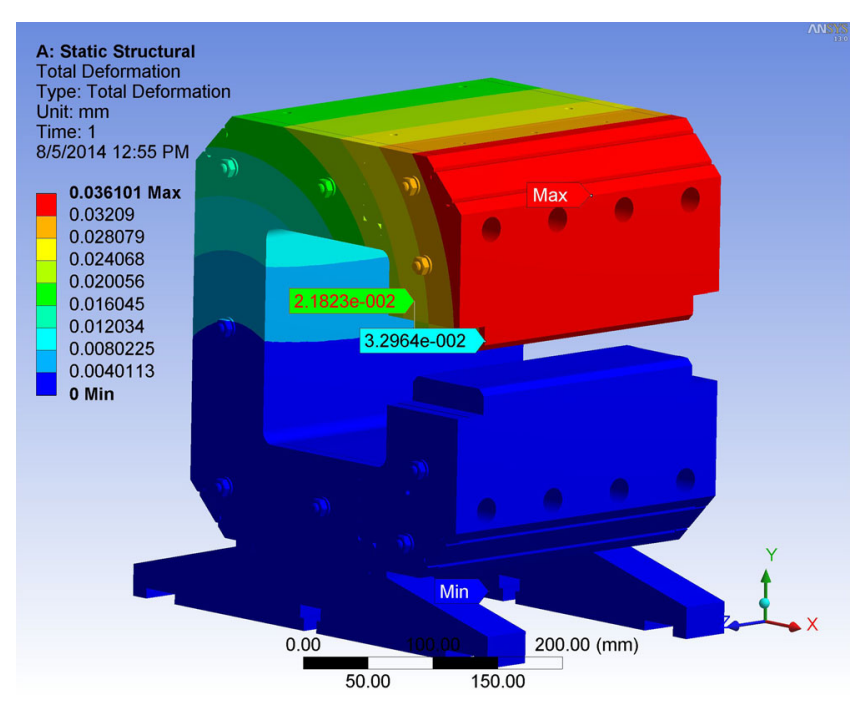

FIG. 10. Static mechanical analysis for one of the sections of the SR dipole magnet.

than $0.04 \mathrm{~mm}$. The deflected pole produces quadrupole gradients of 0.57 Gauss $/ \mathrm{cm}$ and the field quality increases to $1.4 \times 10^{-4}$. However, one can overcome these undesired gradients and pole deflection by subtly having quadrupoles adjusted in the lattice and increasing the width of return yoke or welding a plate to it $[23,26]$.

\section{A. 3D design}

The magnetic length is met by chamfers at the pole ends. The chamfering will additionally control higher integrated multipoles. The outer side of both lateral dipole sections are chamfered. The end pole profile and its roll-off follow the Rogowski curve [27]. The optimized chamfer angle from the pole edge is 52 degrees with the depth of $15 \mathrm{~mm}$ [10]. Thus, the magnetic length at the center $(x=0)$ is $839.5 \mathrm{~mm}$ which is $0.5 \mathrm{~mm}$ less than the desired one. As shown in Fig. 11 the maximum effective length deviation within the

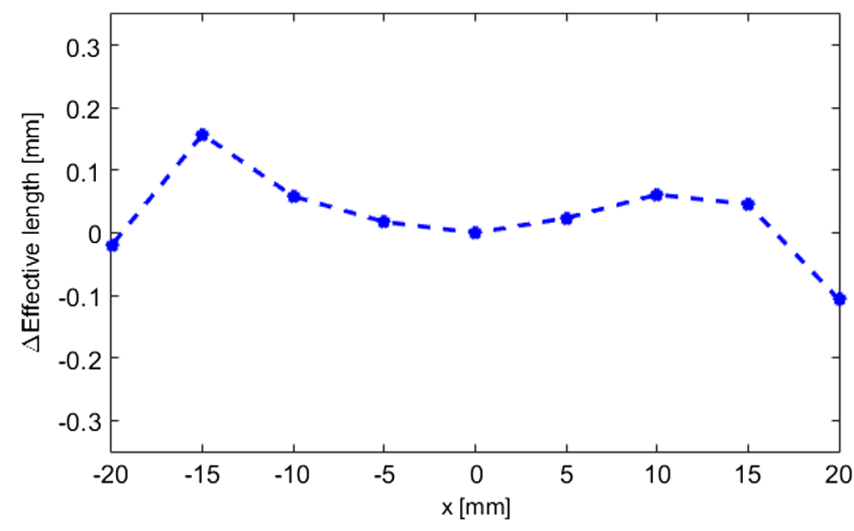

FIG. 11. Effective length variation for the SR dipole magnet with the chamfer.

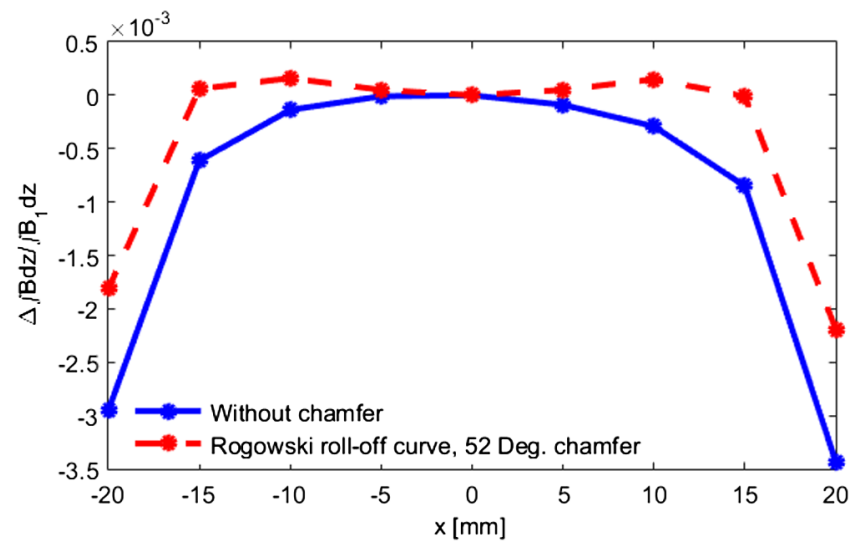

FIG. 12. Integrated field quality of the SR dipole magnet in the $y=0$ plane with and without chamfer.

GFR of $\pm 14 \mathrm{~mm}$ is about $0.15 \mathrm{~mm}$. These results will be further examined prior to proceeding with the procurement exercise for the dipole and, if necessary, small adjustments will be made to the end roll-off to provide the required magnetic length of $840 \mathrm{~mm}$. It is worth mentioning that the iron length of $820 \mathrm{~mm}$ is utilized in the MERMAID code [19].

The integrated field quality with and without chamfering are plotted in Fig. 12 which indicates that the optimized chamfer improves it from $6 \times 10^{-4}$ to $1.5 \times 10^{-4}$ which is less than the desired value of $2 \times 10^{-4}$ within the total GFR.

The designed ILSF dipole magnet is composed of three straight yokes placed on one special girder, that facilitate the replacement of the middle low field dipole section with the high field one with individual hollow conductor coils. The two-side chamfered low field dipole sections are fixed on the girder with the mechanical angle of 1.2 degrees between them and the middle yoke. The shared long hollow conductor coils are mounted around all yokes. The mechanical 3D model of the SR dipole installed on the girder is shown in Fig. 13 (left). Each straight yoke is based on the stacked C-type laminations with the thickness of $1 \mathrm{~mm}$. The laminations are stacked with the packing factor of $98 \%$ by the local epoxy resin of EL-413, with a hardener of HA-41, which is similar to the epoxy resin of Araldite F, with a hardener of ARADUR HY 905. Additionally, several tension plates are also welded at different parts around the yoke to avoid tilting and separating the laminations. The middle yoke lamination consists of a block bottom and a block top half, assembled together, allows replacing the middle yoke with the high field section easily. The installed superbend magnet on the girder is also depicted in Fig. 13 (right).

\section{B. Electrical and cooling calculations}

For electrical and cooling calculations, conductor and cooling duct dimensions should be selected to provide 

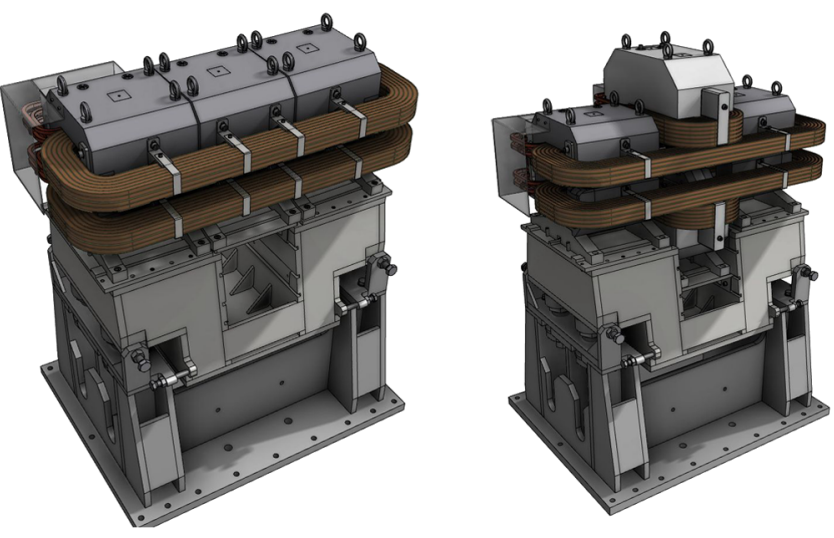

FIG. 13. Perspective mechanical design of the lattice (left) low field dipole and (right) the superbend magnet on the same girder. The lateral low field dipole sections are fixed on the girder but the middle section was installed on different removable plates in both cases [26].

optimal current density, power, inductance, cooling water speed and pressure drop [25]. The oxygen-free copper (OFC) $11 \times 11 \mathrm{~mm}^{2}$ conductor duct with a cooling hole of $4.5 \mathrm{~mm}$ diameter has been chosen. The calculated electrical and cooling parameters of the dipole are given in Table III. The designed cooling water speed is $\leq 4 \mathrm{~m} / \mathrm{s}$ to avoid vibration and erosion of the conductor. Inasmuch as using one cooling system for all SR magnets, the same pressure drop of 6 bar is committed for the whole coils in the calculations.

\section{QUADRUPOLES}

The quadrupole with the maximum field gradient of $24.78 \mathrm{~T} / \mathrm{m}$ and the length of $0.44 \mathrm{~m}$ is simulated with the pole tip field of $0.65 \mathrm{~T}$ [24]. The aperture radius is $26 \mathrm{~mm}$ introducing $2.5 \mathrm{~mm}$ clearance between the pole and the vacuum chamber. The same path is deduced for the rest, as well as decreasing the total current [9].

TABLE III. Electrical and cooling specifications of the SR dipole magnet.

\begin{tabular}{lcc}
\hline \hline Parameter & Unit & Value \\
\hline Amp-turns per pole & A.t & 9168 \\
Number of turns per coil & $\ldots$ & 24 \\
Current density & $\mathrm{A} / \mathrm{mm}^{2}$ & 3.64 \\
Conductor cross section & $\mathrm{mm}^{2}$ & $11 \times 11$ \\
Water cooling tube diameter & $\mathrm{mm}$ & 4.5 \\
Voltage drop per magnet & $\mathrm{V}$ & 8.81 \\
Power per magnet & $\mathrm{kW}$ & 3.37 \\
No. of cooling circuits & $\ldots$ & 4 \\
Water temperature rise & ${ }^{\circ} \mathrm{C}$ & 5.63 \\
Cooling water speed & $\mathrm{m} / \mathrm{s}$ & 2.25 \\
Pressure drop & $\mathrm{bar}$ & 6 \\
\hline \hline
\end{tabular}

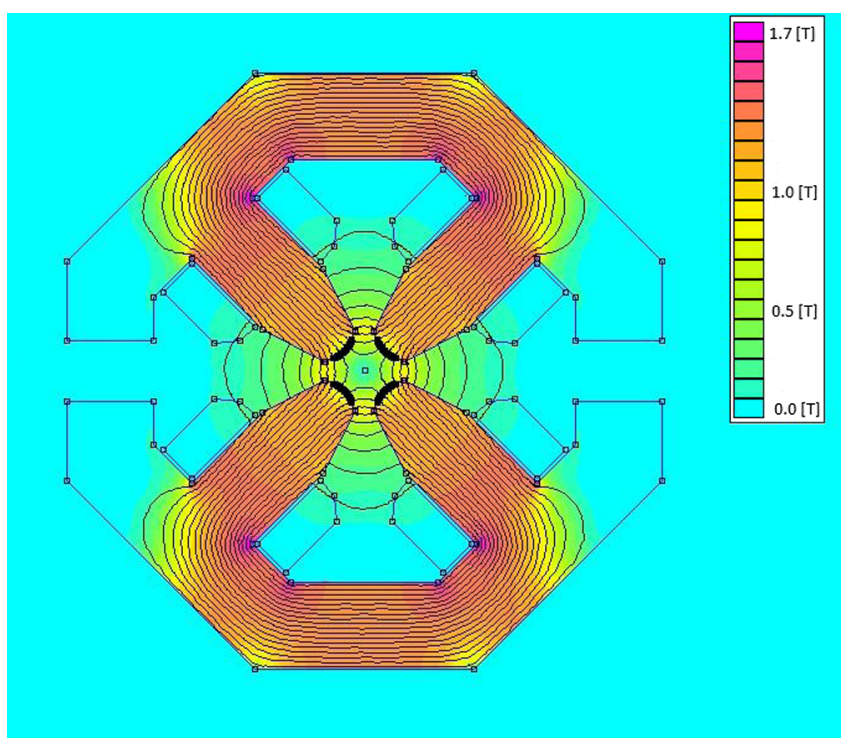

FIG. 14. Magnetic field inside the SR quadrupole magnet. The colors in the yoke correspond to the field values given on the legend.

Figure 14 displays the simulated magnetic field inside the quadrupole where the back legs are removed to accommodate the vacuum antechamber, while keeping the field symmetry. Applying a tangential shim on the pole tip results in the field quality lower than desired value of $0.02 \%$ within the GFR of $\pm 13.5 \mathrm{~mm}$, see Fig. 15. The corresponding 2D mechanical layout is also given in Fig. 16 proposing the lamination dimensions of $275 \times 275 \mathrm{~mm}^{2}$ with $1 \mathrm{~mm}$ thickness. Normalized values of the systematic higher order multipole components, calculated by POISSON code [18], are represented in Fig. 17.

The saturation test was shown in Fig. 18 by sketching the gradient field versus the current. It depicts that the operation current of the quadrupole is $207.1 \mathrm{~A}$, and the

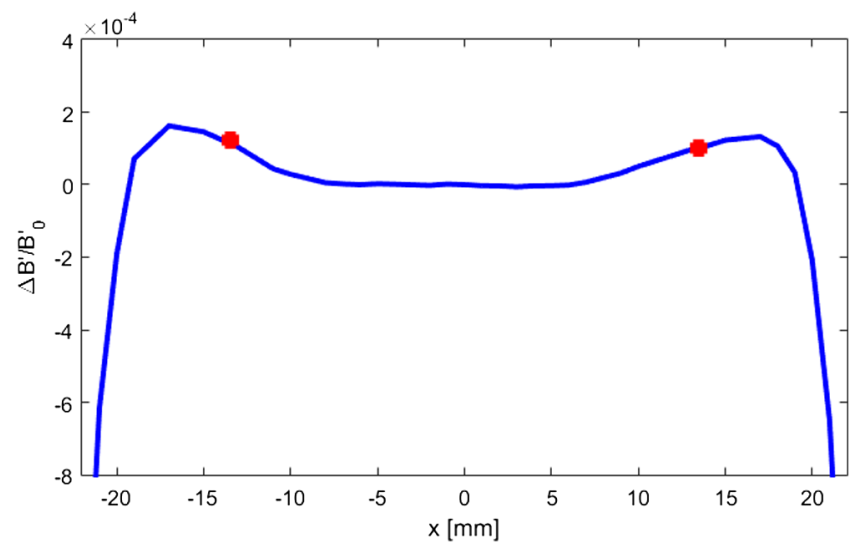

FIG. 15. Quadrupole gradient quality vs horizontal distance. The red points represent $\pm 13.5 \mathrm{~mm}$. 


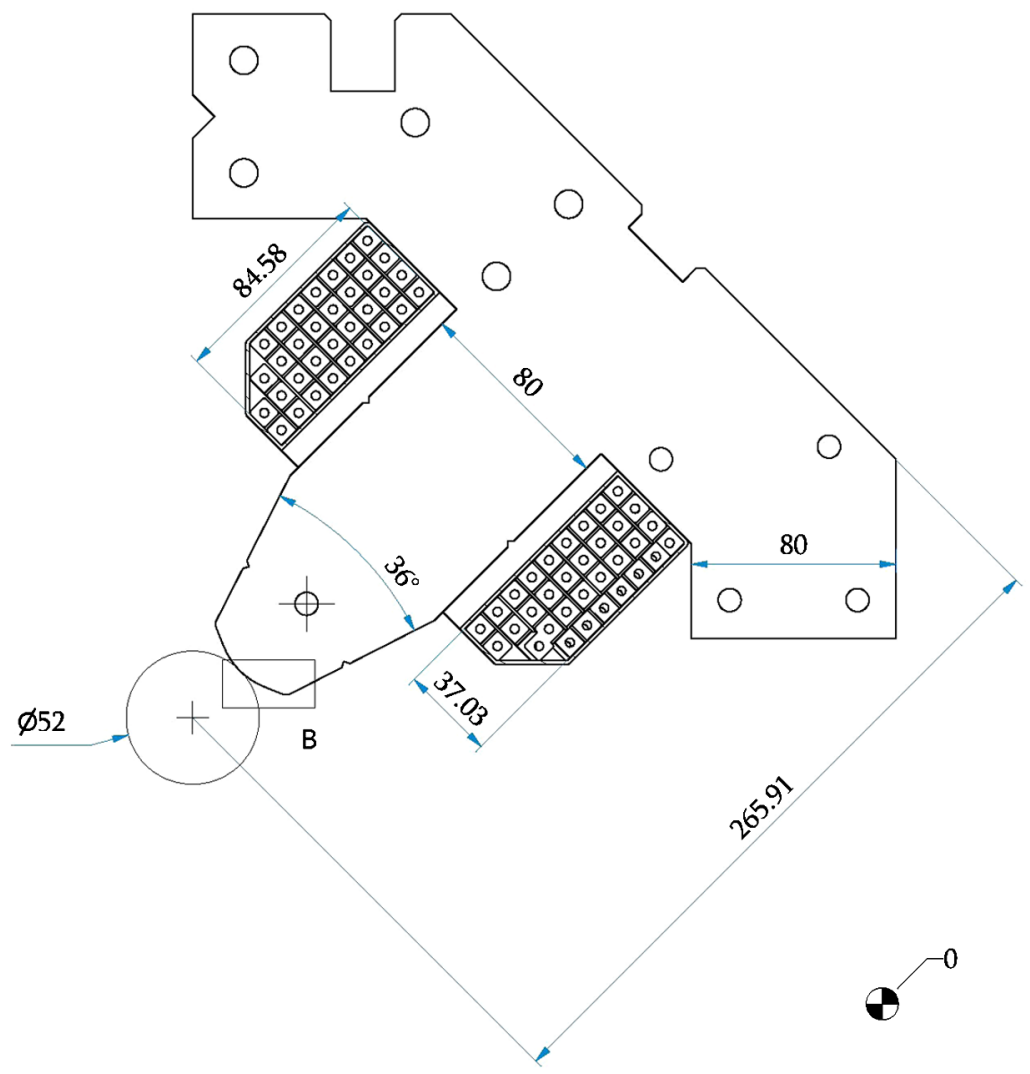

\begin{tabular}{|c|c|c|}
\hline \multicolumn{3}{|c|}{ POSITION TABLE } \\
\hline POSITION & $\mathrm{X}(\mathrm{mm})$ & $\mathrm{Y}(\mathrm{mm})$ \\
\hline 0 & 0.00 & 0.00 \\
\hline 1 & 18.38 & 18.38 \\
\hline 10 & 29.10 & 11.62 \\
\hline 11 & 35.56 & 9.04 \\
\hline 12 & 37.60 & 9.04 \\
\hline
\end{tabular}

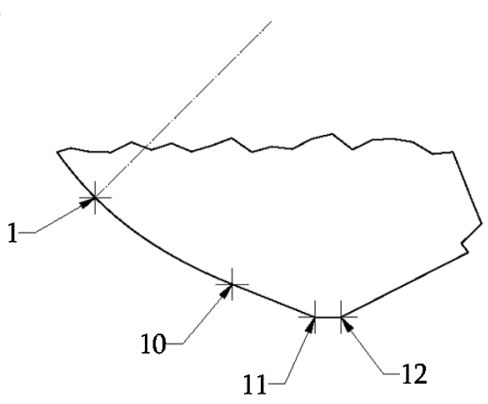

B

FIG. 16. Lamination and coils dimensions of the SR quadrupole magnet and the pole profile coordinates. The profile points 1 to 10 follow a hyperbola equation of $x y=R^{2} / 2$ where $R$ is the quadrupole radius aperture. The scale is millimeter.

deviation from the corresponding linear curve is less than $0.3 \%$.

There seems to be a kind of yoke deflection due to magnetic fields between the poles and their weight. Such spatial deviation can have an effect on the field quality and bring up more tangible multipole components. Figure 19 indicates that how applying endplates will reduce maximum deflection from $0.1 \mathrm{~mm}$ to $0.02 \mathrm{~mm}$.

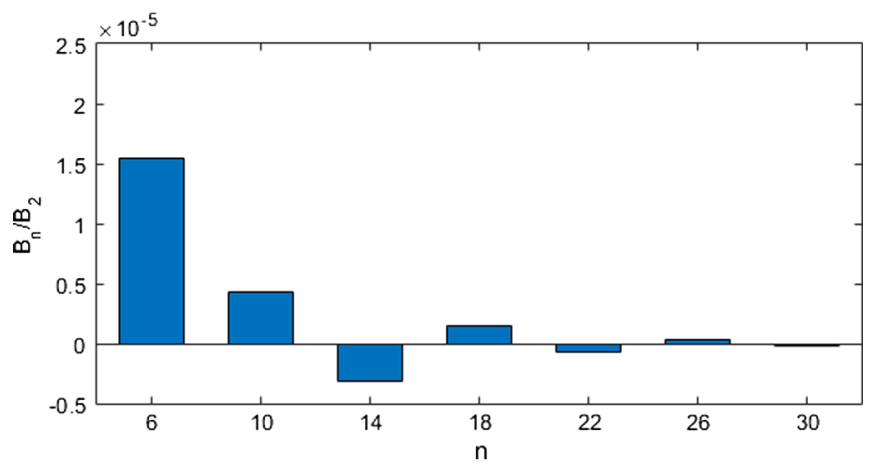

FIG. 17. Normalized systematic higher order multiples at the GFR of $13.5 \mathrm{~mm}$.

\section{A. 3D design}

Required magnetic length with the minimum integral multipoles are realized by a 45 degrees and $7 \mathrm{~mm}$ deep chamfer while the iron yoke length of the simulated quadrupole is assumed to be $405 \mathrm{~mm}$. Figure 20 represents the deviation of magnetic length in the chamfered state,

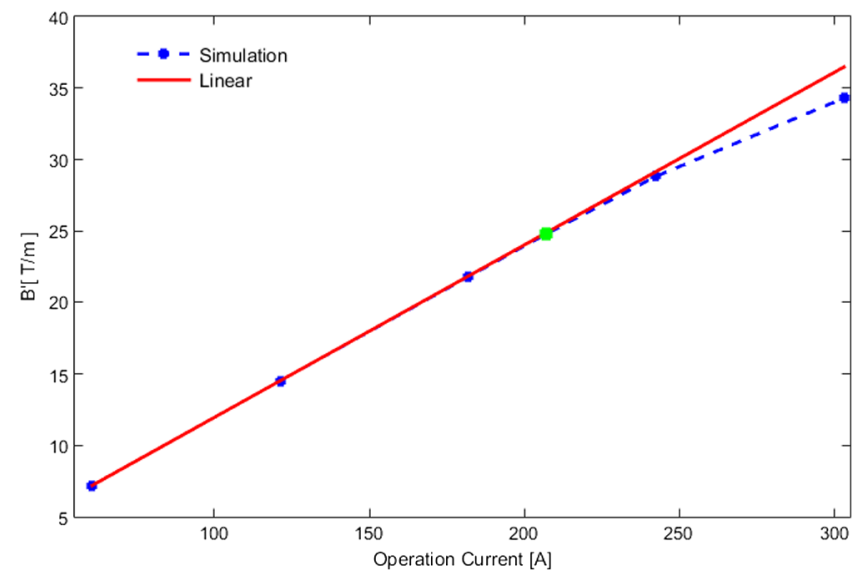

FIG. 18. Gradient field as a function of the operation current of the quadrupole magnet. The green filled circle indicates the 2D designed quadrupole operation current. 

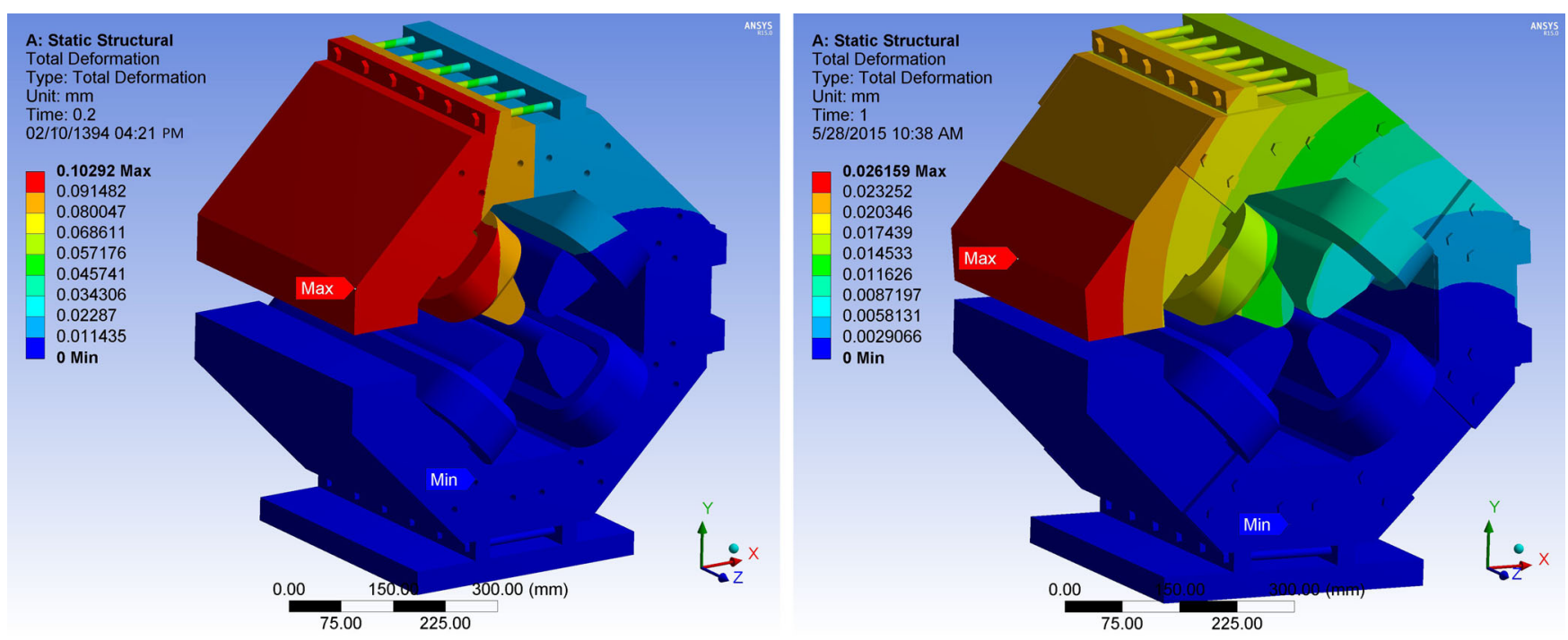

FIG. 19. Static mechanical analysis for the SR quadrupole magnet with (right) and without (left) the endplates.

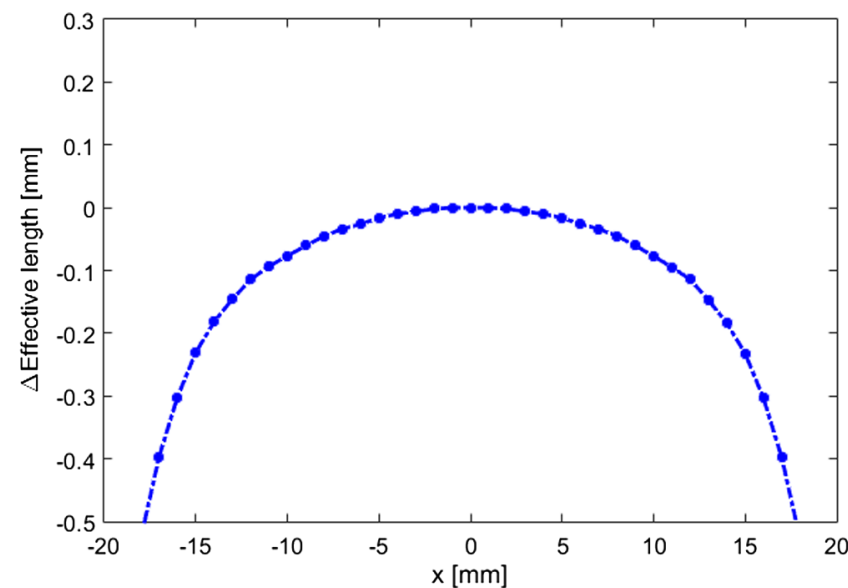

FIG. 20. Effective length variation vs horizontal distance for the $405 \mathrm{~mm}$ long quadrupole after chamfering.

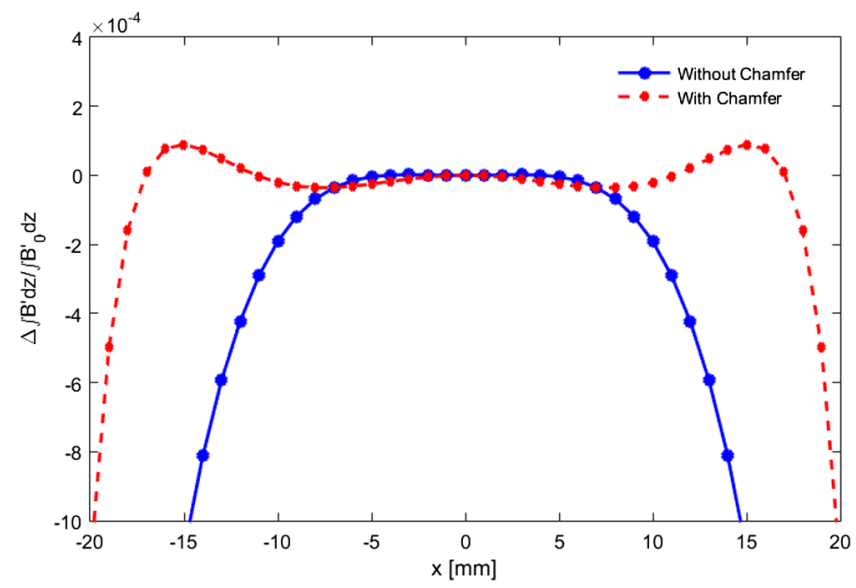

FIG. 21. Integrated gradient field quality vs horizontal distance for a $405 \mathrm{~mm}$ long quadrupole before and after chamfering. with $0.2 \mathrm{~mm}$ anomaly within the GFR. If necessary, small adjustments during measurement will be applied on the end roll-off to provide $440 \mathrm{~mm}$ magnetic length. The integrated gradient field quality of the quadrupole before and after chamfering are compared in Fig. 21. That is rewarding to insure that the field quality improves from $0.1 \%$ to $0.01 \%$ within the GFR.

The final mechanical design of the SR quadrupole, ready for fabrication, is shown in Fig. 22, though the girder and

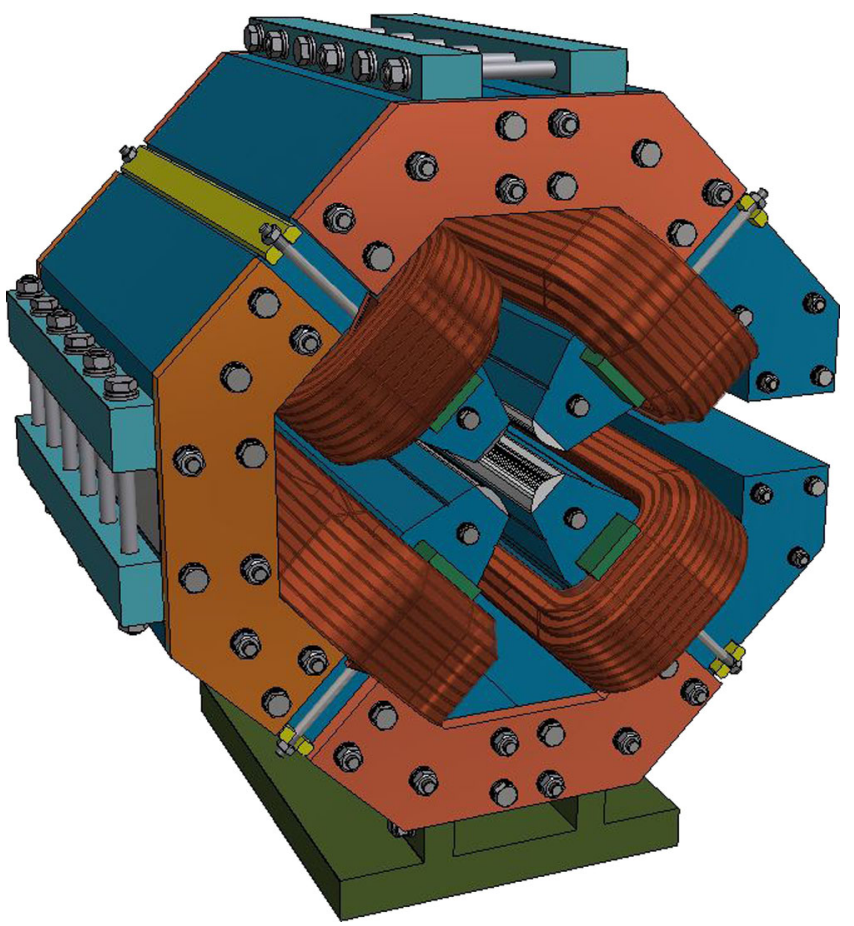

FIG. 22. Perspective mechanical design of the SR quadrupole with the endplates [26]. 
TABLE IV. Electrical and cooling specifications of the SR quadrupole magnet.

\begin{tabular}{lcc}
\hline \hline Parameter & Unit & Value \\
\hline Amp-turns per pole & A.t & 6835 \\
Number of turns per coil & $\ldots$ & 33 \\
Current density & $\mathrm{A} / \mathrm{mm}^{2}$ & 4.44 \\
Conductor cross section & $\mathrm{mm}^{2}$ & $7.5 \times 7.5$ \\
Water cooling tube diameter & $\mathrm{mm}$ & 3.5 \\
Voltage drop per magnet & $\mathrm{V}$ & 11.3 \\
Power per magnet & $\mathrm{kW}$ & 2.34 \\
No. of cooling circuits & $\ldots$ & 4 \\
Water temperature rise & ${ }^{\circ} \mathrm{C}$ & 8.12 \\
Cooling water speed & $\mathrm{m} / \mathrm{s}$ & 1.79 \\
Pressure drop & $\mathrm{bar}$ & 6 \\
\hline \hline
\end{tabular}

tilting issues are dissociated. One of the spacers is filled with the stainless steel block for assembling. It is worth mentioning that the low carbon steel ST52 endplates with $15 \mathrm{~mm}$ thickness are employed to stack the laminations. Its hysteresis curve is similar to that for the magnet steel and therefore these endplates are included in the adopted iron length.

\section{B. Electrical and cooling calculations}

The calculated electrical and cooling parameters of the SR quadrupole follow Table IV. Conductor and cooling duct of $7.5 \times 7.5 \mathrm{~mm}^{2}$ dimensions with the cooling tube diameter of $3.5 \mathrm{~mm}$ is selected to afford optimum current density, power, inductance, cooling water speed and pressure drop here too. The 6 bar pressure drop is regarded to cope well with the unique SR cooling system [25].

\section{SEXTUPOLES}

ILSF storage ring sextupole magnets are in 8 families with additional coils for horizontal, vertical and skew quadrupole corrections.

The sextupole magnet has been designed with three-fold symmetry with one horizontal air gap where the back leg is removed to accommodate the antechamber of the vacuum chamber. Furthermore, other triplets are connected mechanically with the stainless steel spacers all along assembling. It is needed to consider when the trim coils are implemented and antechamber is wide enough to pass through the back leg, the yoke is attached by special parts with the same yoke material to preserve correctors' field symmetry.

The maximum sextuple component was taken to be $1200 \mathrm{~T} / \mathrm{m}^{2}$ and consequently the pole tip field of $0.4 \mathrm{~T}$ [9]. The aperture radius of $26 \mathrm{~mm}$ has led to $0.5 \mathrm{~mm}$ clearance between the pole and the vacuum chamber [24]. The simulated magnetic field of the sextupole magnet without trim coils is shown in Fig. 23. Figure 24 depicts the corresponding sextupole component quality, lower than

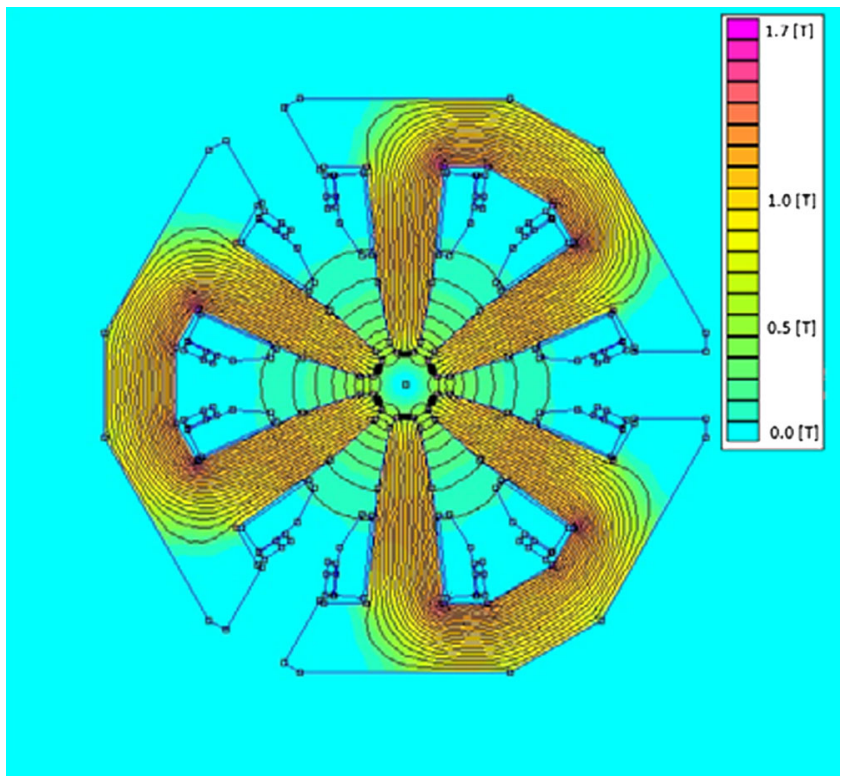

FIG. 23. Magnetic field inside the SR sextupole magnet. The colors in the yoke correspond to the field values given on the legend.

$0.02 \%$ within $\pm 13.5 \mathrm{~mm}$ GFR. The $2 \mathrm{D}$ mechanical layout of the sextupole magnet proposing total lamination dimensions of $230 \times 260 \mathrm{~mm}^{2}$ with $1 \mathrm{~mm}$ thickness is shown in Fig. 25.

The normalized values of systematic higher order multipoles by POISSON are represented in Fig. 26. These errors are nominal enough to range in the field quality gamut. The higher integrated multipoles are adequately small to exclude the necessity of any chamfer in 3D design. So that, the $344 \mathrm{~mm}$ iron length was assumed to reach to the $360 \mathrm{~mm}$ desired magnetic length.

The saturation test is shown in Fig. 27 by sketching the sextupole component versus the current. It depicts that the

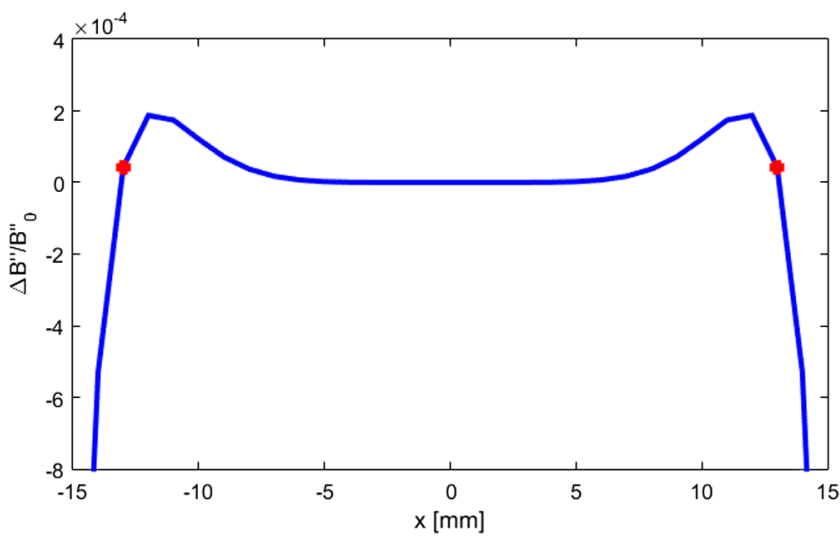

FIG. 24. Sextupole component quality vs horizontal distance. The red points represent $\pm 13.5 \mathrm{~mm}$ GFR. 


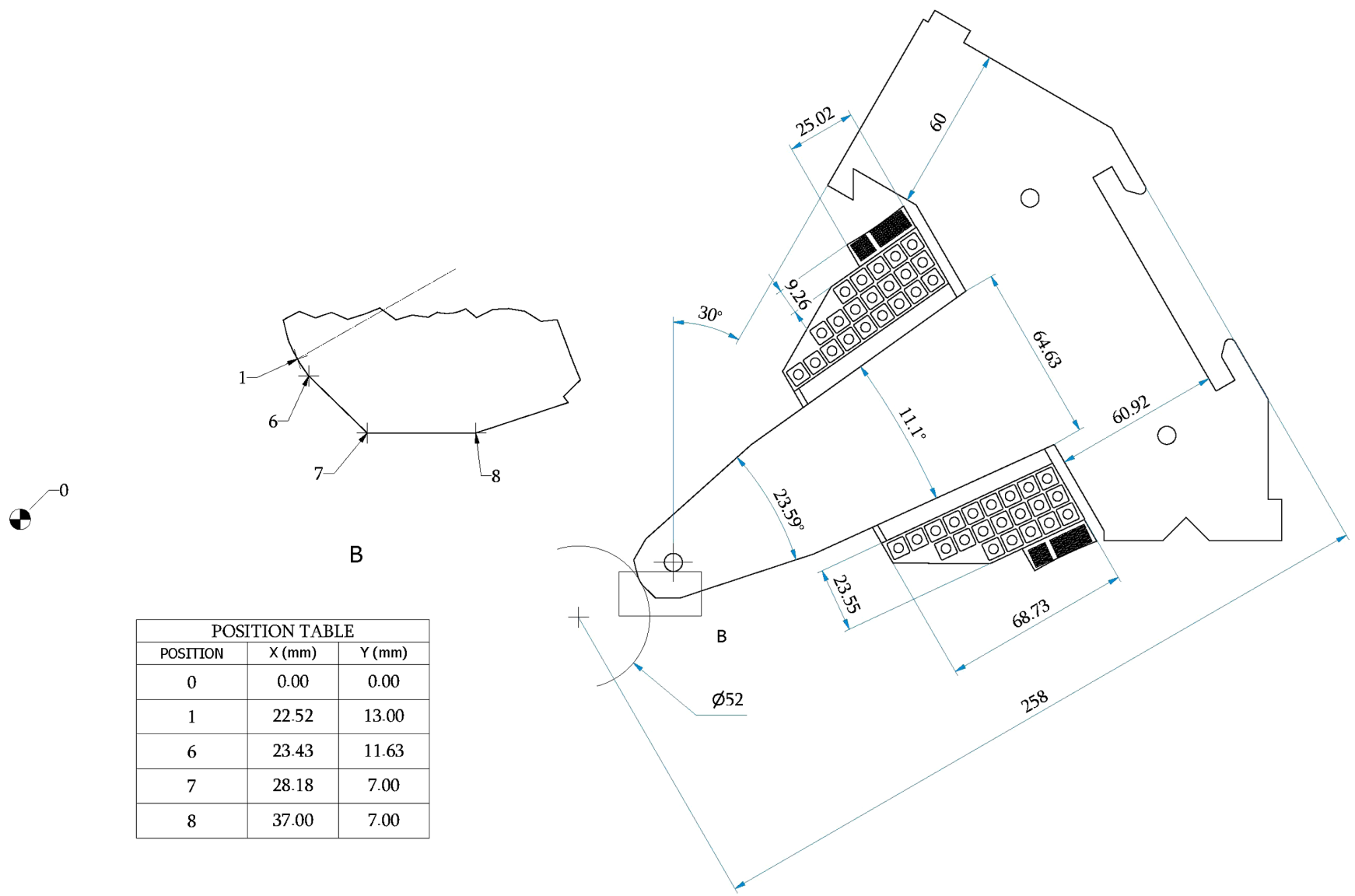

FIG. 25. Lamination and coils dimensions of the SR sextupole magnet and the pole profile coordinates. The profile points 1 to 6 follow a particular equation of $3 x^{2} y-y^{3}=R^{3}$ where $R$ is the sextupole radius aperture. The scale is millimeter.

operation current of the sextupole is $140.1 \mathrm{~A}$, which is at the end of the linear regime.

The yoke deflection by magnetic field between the poles and their weight, which cause some distortion in the field

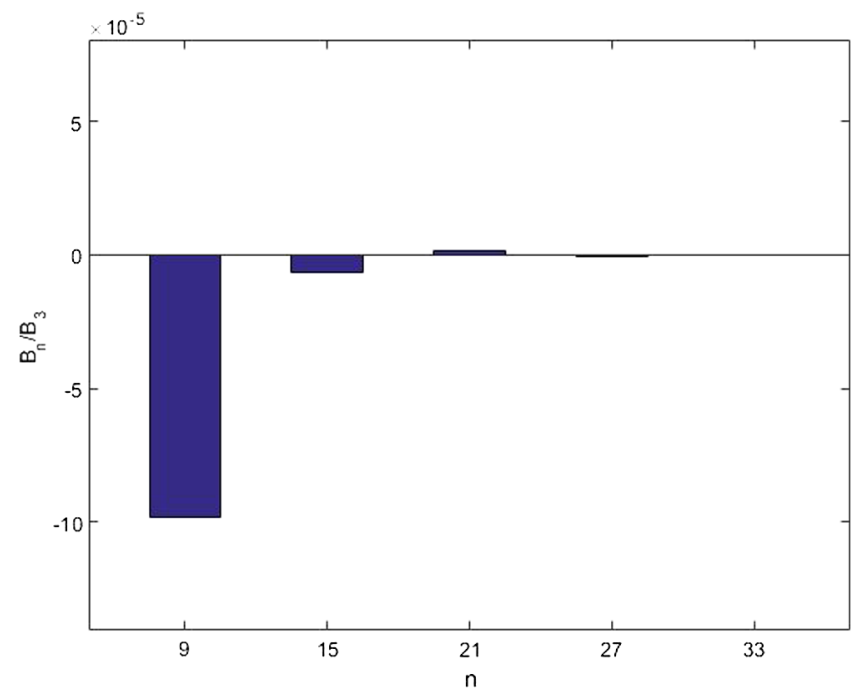

FIG. 26. Normalized systematic higher order multipoles at the reference radius of $13.5 \mathrm{~mm}$. quality, could be controlled by practicing endplates again. Such endplates represented in Fig. 28 have reduced the maximum deflection from $0.2 \mathrm{~mm}$ to $0.004 \mathrm{~mm}$. The low carbon steel ST52 endplates with $12 \mathrm{~mm}$ thickness are

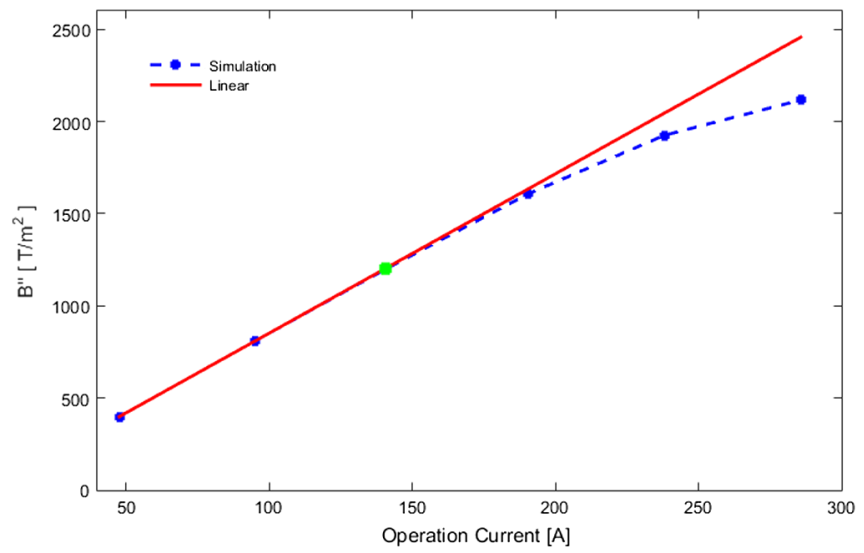

FIG. 27. Sextupole component as a function of the operation current of the sextupole magnet. The green filled circle indicates the 2D designed sextupole operation current. 

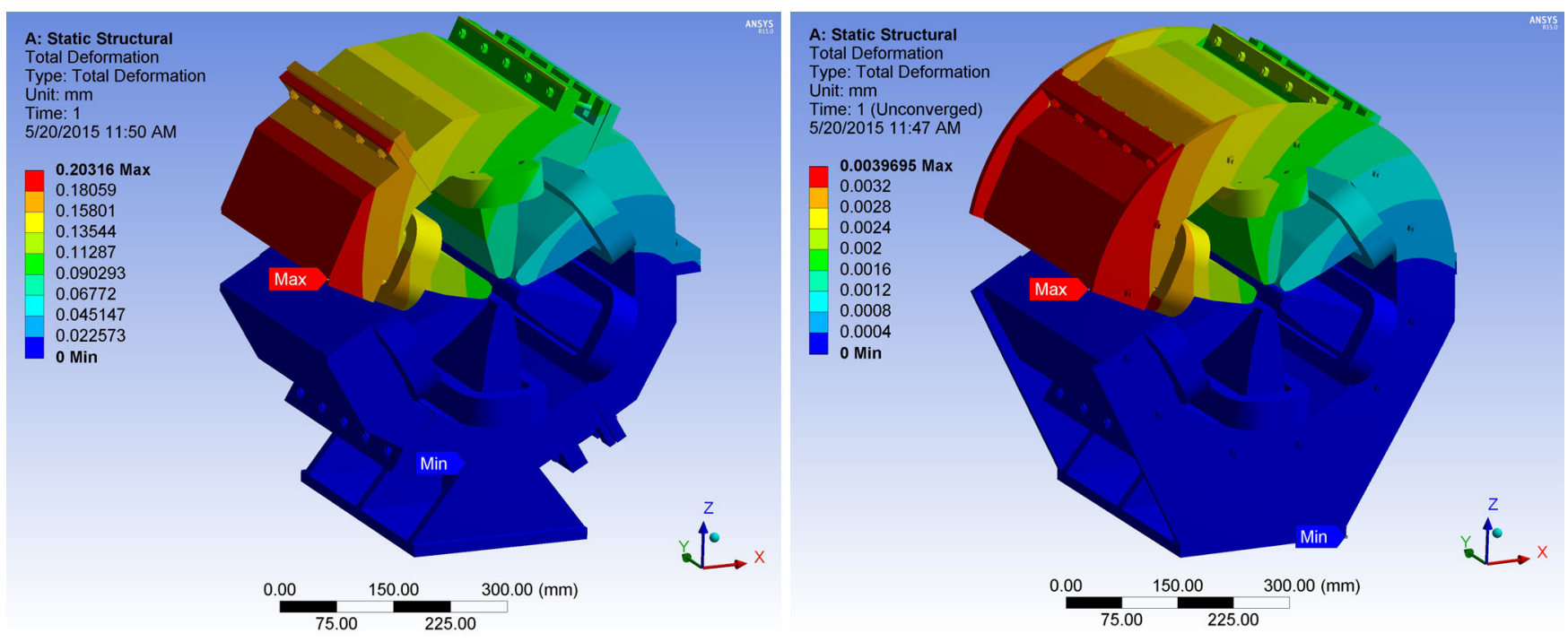

FIG. 28. Static mechanical analysis for the SR sextupole magnet, without (left) and with (right) the endplates.

employed to stack the laminations and are enclosed in the iron length.

The mechanical design of the SR sextupole also has been finalized and it is in the fabrication process. Figure 29 depicts two cases of one with three-fold symmetry with one horizontal air gap and another with the same pole profile but connected laminations with the same yoke material extra parts.

\section{A. Correctors}

The sextupole magnets have additional coils for horizontal, vertical correctors with maximal angle of $0.175 \mathrm{mrad}$, and skew quadrupole correctors. The coils are powered according to Fig. 30 depending on the desired corrections.

The geometrical portrait and optimized transverse field of these correctors are shown in Figs. 31, 32, and 33, respectively. The expected magnetic field for dipolar
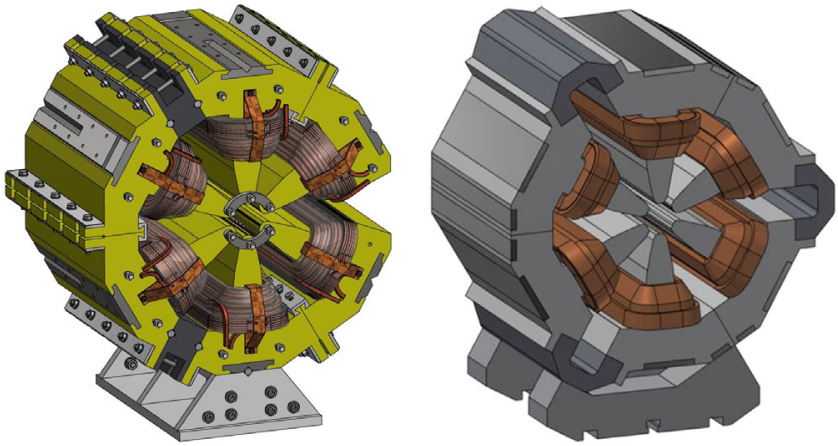

FIG. 29. Perspective mechanical design of the SR sextupoles with one horizontal air gap and two non-magnetic steel blocks (left) and with connective magnetic steel blocks (right) [26]. correctors is $4.8 \mathrm{mT}$. The field profile of the skew quadrupole for the horizontal $\left(B_{x}\right)$ and the vertical $\left(B_{y}\right)$ components in the region neighboring the magnetic center is much more linear and the gradient for the $\mathrm{x}$ and $\mathrm{y}$ planes are around $0.1(\mathrm{~T} / \mathrm{m})$ [28].

\section{B. Electrical and cooling calculations}

The electrical and cooling parameters of the designed sextupole are displayed in Table V. The selected hollow

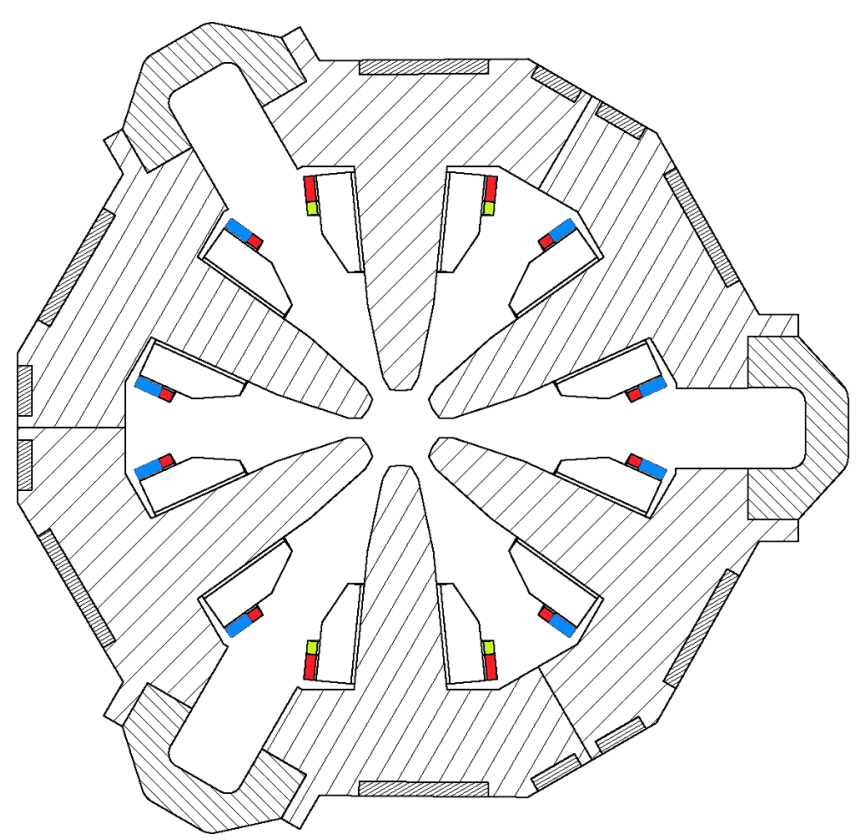

FIG. 30. Coils configurations for the horizontal, vertical and skew quadrupole correctors which are indicated by red, blue and green colors respectively. 

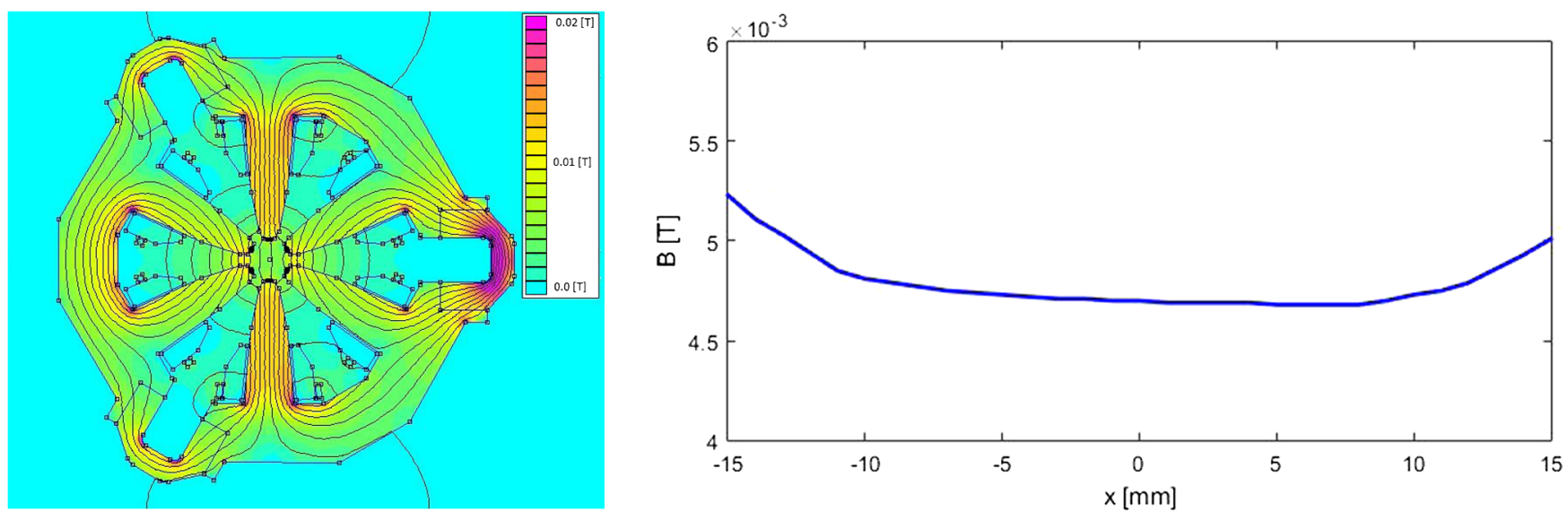

FIG. 31. Field distribution of the horizontal corrector (left) and designed magnetic field vs horizontal distance (right).
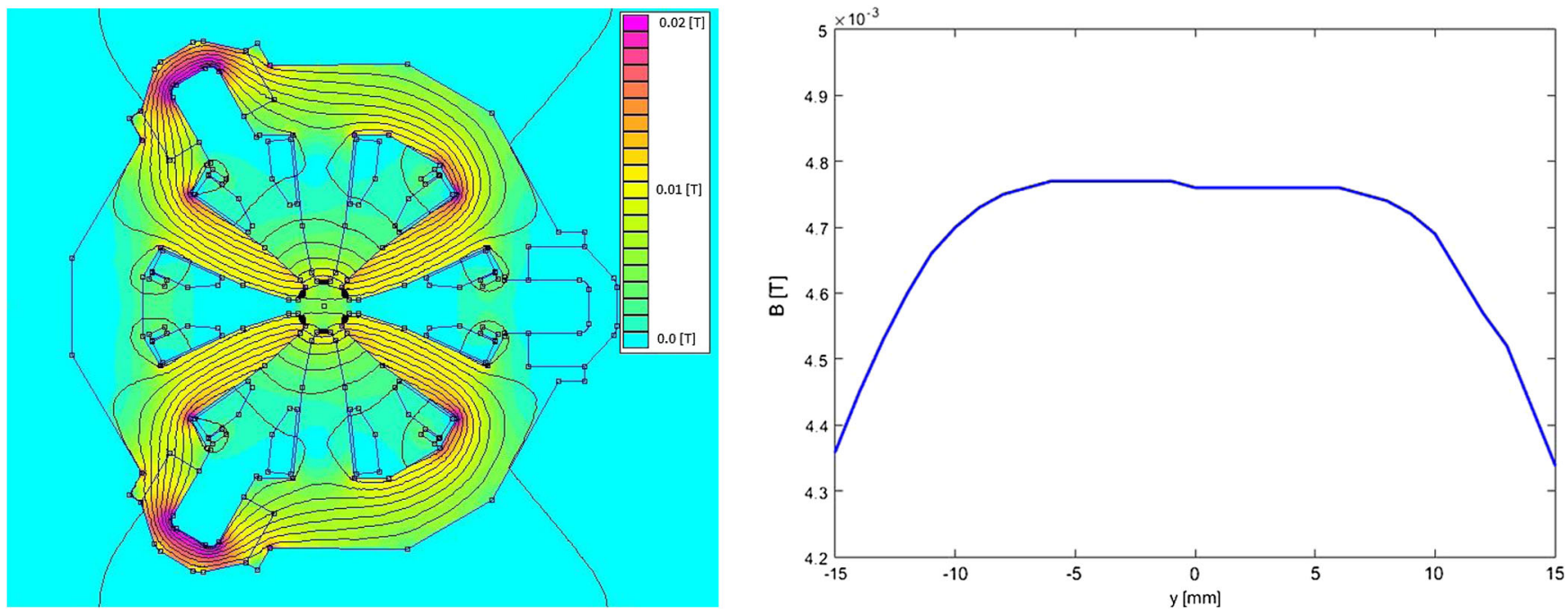

FIG. 32. Field distribution of the vertical corrector (left) and designed magnetic field vs vertical distance (right).
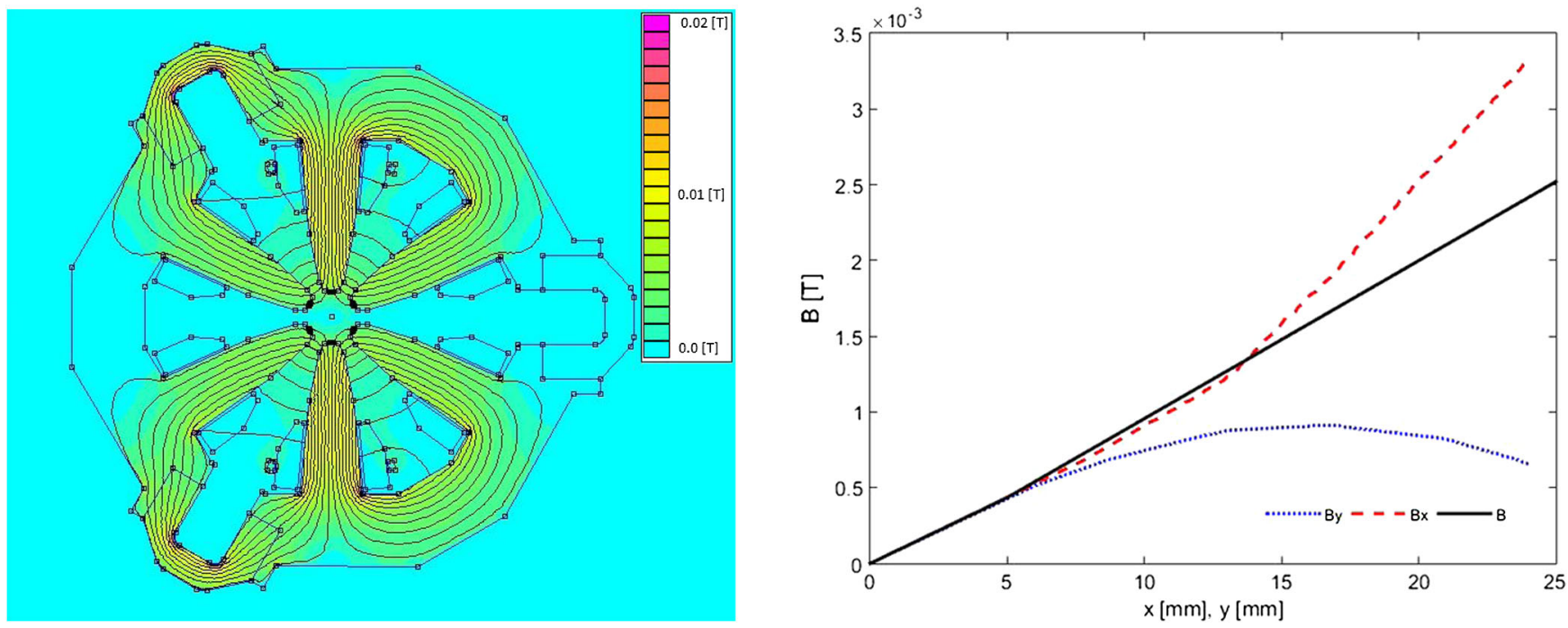

FIG. 33. Field distribution of the skew quadrupole corrector (left) and designed magnetic field vs distance (right). 
TABLE V. Electrical and cooling specifications of the SR sextupole magnet.

\begin{tabular}{lcc}
\hline \hline Parameter & Unit & Value \\
\hline Amp-turns per pole & A.t & 2957 \\
Number of turns per coil & $\ldots$ & 21 \\
Current density & $\mathrm{A} / \mathrm{mm}^{2}$ & 4.31 \\
Conductor cross section & $\mathrm{mm}^{2}$ & $6.5 \times 6.5$ \\
Water cooling tube diameter & $\mathrm{mm}$ & 3.5 \\
Voltage drop per magnet & $\mathrm{V}$ & 8.67 \\
Power per magnet & $\mathrm{kW}$ & 1.22 \\
No. of cooling circuits & $\ldots$ & 3 \\
Water temperature rise & ${ }^{\circ} \mathrm{C}$ & 5.81 \\
Cooling water speed & $\mathrm{m} / \mathrm{s}$ & 1.74 \\
Pressure drop & $\mathrm{bar}$ & 6 \\
\hline \hline
\end{tabular}

TABLE VI. Typical electrical corrector specifications.

\begin{tabular}{|c|c|c|c|}
\hline Parameters & $\begin{array}{l}\text { Horizontal } \\
\text { Corrector }\end{array}$ & $\begin{array}{l}\text { Vertical } \\
\text { Corrector }\end{array}$ & $\begin{array}{c}\text { Skew } \\
\text { Quadrupolar } \\
\text { Corrector }\end{array}$ \\
\hline @ $3 \mathrm{GeV}(\mathrm{mrad})$ & 0.175 & 0.175 & \\
\hline Magnetic field $(\mathrm{T})$ & 4.8 E-3 & $4.8 \mathrm{E}-3$ & $\begin{array}{l}2.08 \text { E-3 } \\
\text { (pole tip field) }\end{array}$ \\
\hline $\begin{array}{l}\text { Ampere-Turns per } \\
\text { pole (A.t) }\end{array}$ & $128(2)+64(4)$ & $112(4)$ & $64(2)$ \\
\hline Turns per coil (I) & $32+16$ & 32 & 16 \\
\hline $\begin{array}{l}\text { Conductor size } \\
\left(\mathrm{mm}^{2}\right)\end{array}$ & $3.15 \times 0.5$ & $3.15 \times 0.5$ & $3.15 \times 0.5$ \\
\hline $\begin{array}{l}\text { Magnet inductance } \\
(\mathrm{mH})\end{array}$ & 88 & 95.6 & 9.94 \\
\hline Current (A) & 4 & 3.5 & 4 \\
\hline Total voltage (V) & 17.7 & 20.6 & 2.94 \\
\hline Total power (W) & 71 & 72.16 & 11.8 \\
\hline
\end{tabular}

conductor dimensions are $6.5 \times 6.5 \mathrm{~mm}^{2}$ with the cooling duct diameter of $3.5 \mathrm{~mm}$. All conductor dimensions are chosen in favor of optimum outcomes. The 6 bar pressure drop is reserved for all coils in the storage ring too. Table VI summarizes the main electrical corrector parameters. Corrector coils are solid conductors due to the nominal range of consumed power [25].

\section{CONCLUSIONS}

The design of the ultralow emittance ILSF storage ring magnets have been physically and mechanically described. The proper shims and end chamfers for them are developed and fully determined to meet the field quality and integrated field uniformity requirements. The designed SR magnets are now ready for fabrication as prototypes for the ILSF.

\section{ACKNOWLEDGMENTS}

The authors would like to specially thank H. Wiedemann for his many helpful comments on this research. We are grateful to mechanic group of ILSF especially V. Moradi and J. Dehghani for mechanical designs and drawings.

[1] J. Rahighi, in Proceedings of the International Particle Accelerator Conference, Kyoto, Japan (ICR, Kyoto, 2010), p. 2532; http://ilsf.ipm.ac.ir/.

[2] J. Rahighi et al., in Proceedings of the 2nd International Particle Accelerator Conference, San Sebastián, Spain (EPS-AG, Spain, 2011), p. 2954.

[3] Y. Papaphilippou, A. Ropert, P. Elleaume, and L. Farvacque, in Proceedings of the 21st Particle Accelerator Conference, Knoxville, TN, 2005 (IEEE, Piscataway, NJ, 2005), p. 1.

[4] S. Ozaki, J. Bengtsson, S. L. Kramer, S. Krinsky, and V. N. Litvinenko, in Proceedings of the 22nd Particle Accelerator Conference, PAC-2007, Albuquerque, NM (IEEE, New York, 2007), p. 77.

[5] M. Borland, G. Decker, L. Emery, V. Sajaev, Y. Sun, and A. Xiao, Lattice design challenges for fourth-generation storage-ring light sources, J. Synchrotron Radiat. 21, 912 (2014).

[6] P. F. Tavares, S. C. Leemann, M. Sjöström, and A. Andersson, The MAX IV storage ring project, J. Synchrotron Radiat. 21, 862 (2014).

[7] J.-L. Revol et al., in Proceedings of the 4th International Particle Accelerator Conference, Shanghai, China (JACoW, Shanghai, China, 2013), p. 82.

[8] L. Liu, N. Milas, A. H. C. Mukai, X. R. Resende, and F. H. de Sá, The Sirius project, J. Synchrotron Radiat. 21, 904 (2014).

[9] H. Ghasem, E. Ahmadi, F. Saeidi, and K. Sarhadi, Beam dynamics of a new low emittance third generation synchrotron light source facility, Phys. Rev. ST Accel. Beams 18, 030710 (2015).

[10] F. Saeidi, R. Pourimani, J. Rahighi, H. Ghasem, and M. Lamehi Rachti, Normal conducting superbend in an ultralow emittance storage ring, Phys. Rev. ST Accel. Beams 18, 082401 (2015).

[11] J. Guo and T. Raubenheimer, in Proceedings of the 8th European Particle Accelerator Conference, Paris, 2002 (EPS-IGA and CERN, Geneva, 2002), p. 1.

[12] R. Nagaoka and A. Wrulich, Emittance minimization with longitudinal dipole field variation, Nucl. Instrum. Methods Phys. Res., Sect. A 575, 292 (2007).

[13] Y. Papaphilippou and P. Elleaume, in Proceedings of the 21st Particle Accelerator Conference, Knoxville, TN, 2005 (IEEE, Piscataway, NJ, 2005), p. 1.

[14] A. Streun and A. Wrulich, Compact low emittance light sources based on longitudinal gradient bending magnets, Nucl. Instrum. Methods Phys. Res., Sect. A 770, 98 (2015).

[15] A. Shahveh et al., ILSF magnet internal Report No. ILSFMG-TN-RE07-01-20130701, 2013.

[16] A. Shahveh et al., ILSF magnet internal Report No. ILSFMG-TN-RE17-00-20140501, 2014.

[17] Finite Element Method Magnetics (FEMM); www.FEMM info.

[18] POISSON code, Los Alamos National Laboratory Report No. LA-UR-87-126, 1987. 
[19] MERMAID code, SIM Limited, Novosibirsk department, 630058 Novosibirsk, P. O. Box 160, Russia.

[20] RADIA magnet design code; http://ftp.esrf.eu/pub/ InsertionDevices/.

[21] M. Jafarzadeh and E. Yosefi, Power supply group internal report, 2015.

[22] H. Tarawneh, L.-J. Lindgren, and B. Anderberg, Prototype soft end dipole magnet for MAX-IV, fabrication and measurements, Nucl. Instrum. Methods Phys. Res., Sect. A 546, 620 (2005).

[23] H. Wiedemann (private communication).
[24] O. Seify, Vacuum group internal Report No. ILSF-B-VGSR00-DES-02-00I, 2014.

[25] J. Tanabe, Iron Dominated Electromagnets Design, Fabrication, Assembly and Measurements (World Scientific, Singapore, 2005).

[26] J. Dehghani, V. Moradi, M. Hashemi et al., ILSF mechanics internal report, 2015.

[27] DIAMOND Light Source Detailed Design Report, 2002.

[28] S. Varnasseri, in Proceedings of the 10th European Particle Accelerator Conference, Edinburgh, Scotland, 2006 (EPS-AG, Edinburgh, Scotland, 2006), p. 2553. 